\title{
FORMAS TUMULARES E PROCESSOS SOCIAIS NOS CEMITÉRIOS BRASILEIROS
}

\section{Antonio Motta}

Uma das primeiras práticas socioculturais de que se tem notícia é a ocultação do cadáver como meio de preservar os vivos da decomposição de seus mortos. Inumado, queimado, embalsamado, exposto ao ar livre, no cume de montanhas, depositado nas correntezas de rios, exposto para visitação, em casa, em funeral home, no drive-up funeral home ${ }^{1}$ ou até mesmo em velório virtual, o cadáver é o elemento decisivo e primordial que orienta práticas e ritos funerários dos grupos humanos, um dos primeiros registros e testemunhos de sua história. Aliás, foi Robert Hertz um dos primeiros a chamar a atenção para o fato de que é o próprio corpo do morto o objeto sobre o qual a atividade coletiva irá atuar e se exprimir depois da morte, sob formas ritualizadas (Hertz, 1980, p. 90).

Nas sociedades ocidentais buscou-se sempre preservar ou guardar os vestígios dos mortos, seja por meio da construção de túmulos monumen-

Artigo recebido em novembro/2008

Aprovado em junbo/2009 tais, como em algumas civilizações do passado e também nos primeiros cemitérios secularizados, seja em suas versões contemporâneas, nos cemitérios-jardins ou nos cemitérios verticais, nos quais apenas se afixa o nome do morto para identificar o local de sepultamento. Atualmente, em sua forma de expressão menos convencional, os vestígios do morto são apenas confirmados pela gestão afetiva da memória, quando o túmulo não é mais inscrição do corpo a um determinado lugar, quando o cadáver é cremado e suas cinzas, espargidas no ar.

Os dispositivos funerários e as formas de enterramento também vêm acompanhando mudanças significativas nas relações afetivas que os vivos estabelecem com os seus mortos. Morrer com o se nasceu, no quarto de casa, cercado pela família, deixou de ser uma prática comum na maioria das sociedades ocidentais contemporâneas, preferindo-se submeter a morte e o moribundo à economia de mercado, em clínicas e hospitais, longe dos 
olhos, do que conservá-lo no interior do convívio doméstico. É certo que nas chamadas sociedades tradicionais havia uma maior proximidade e familiaridade social com a morte, reforçada mediante atividades simbólicas diversas que favoreciam a repetição de formas ritualizadas, propiciando aquilo a que Marcel Mauss se referiu como sendo "expressões obrigatórias de sentimentos" e que, por sua vez, contribuíam para a construção coletiva das relações sociais (Mauss, 1921).

O mesmo não se observa em relação à dramaturgia contemporânea da morte, com seus ritos e lugares de enterramento, que cada vez mais conferem ao protocolo lúgubre o caráter de simulacro ou de dissimulação, em que o morto é privado de sua própria morte e a família, do luto. E o que dizer dos vestígios do morto, dos túmulos e dos disfarces com que os vivos se compraziam em eternizar seus desaparecidos, por meio de costumes e práticas mortuárias que no passado desempenharam um papel importante no campo ritual e na configuração do espaço de enterramento?

Os novos espaços cemiteriais parecem refletir um outro tipo de realidade: superfícies gramadas, com jardins que mais se assemelham à imagem do Éden e sua eterna primavera, parques temáticos espetacularizados que conferem ao espaço do morto a inequívoca marca do kitsch funerário high tech ou, ainda, luxuosos edifícios, de altos andares, que abrigam os lugares para enterramento individual, equipados com os mais modernos recursos tecnológicos para o conforto e bem estar da família do morto, muitas vezes a se confundir em seu aspecto exterior com verdadeiros prédios de apartamento ou hotéis de luxo.

Neles há também um elemento comum: não há referência explícita à morte, nem tampouco ao morto. A preocupação com o espaço, antes de tudo, é torná-lo aparentemente contraditório com aquilo que efetivamente se destina a oferecer: as inumações ou cremações. Em vez das evidências alegóricas encontradas nos antigos cemitérios oitocentistas, com seus cenários operáticos, de convulsiva dramaticidade, o que os novos espaços de enterramento se propõem é diluir todo e qualquer resquício da morte. Quanto menos evidente, mais distante é a idéia da morte, quanto mais nega-se a morte, menor é a força de sua alteridade e a grandeza de sua atração, concebidos na busca de "apagar no Morto o grande castigo da Morte". ${ }^{2}$

Todavia, o que o leitor encontrará neste ensaio não é nenhuma reflexão teórica ou hitórica sobre a morte, nem sobre suas formas de expressão ritualizadas mais conhecidas: de dor, de sofrimento ou de aflição, tampouco sobre a dimensão transcendental, escatológica ou religiosa, que indivíduos e grupos sociais preferem atribuir à finitude. O que realmente interessa e mobiliza o foco desta análise é o corpo do morto e o tratamento social a ele dispensado, apreendidos a partir de lógicas particulares de sepultamento. De que maneira se pode ler e entender atitudes e significados sociais a partir de um sistema de objetos funerários, isto é, através de vestígios materiais encontrados nos cemitérios? Não se trata de substituir enunciados por objetos ou viceversa, mas identificar e localizar na cultura material funerária elementos que possibilitem dar sentido e significado à linguagem social de uma determinada época, ao mesmo tempo em que permitam entender suas diferentes dinâmicas socioculturais. Tanto as práticas de enterramento, concebidas sob diferentes tipos de morfologias tumulares, como os epitáfios, os adornos e as representações estatuárias, constituem elementos reveladores da organização social, das representações de mundo e de pessoa. Quando submetido à leitura, os dispositivos funerários plasmado nos túmulos permitem traduzir não só acomodações e equilíbrios, mas também tensões e mudanças operadas no contexto de um grupo específico ou no corpo social mais amplo; assim como é também capaz de revelar atos institucionais e de condutas sociais e morais diversos, tendo sempre como preocupação dar sentido e significado a alguma coisa.

No passado os mortos foram objeto de interesses e de cuidados específicos, hoje relegados uns, esquecidos e ignorados outros, o que se converte em importante dispositivo heurístico para se compreender as dinâmicas sociais aqui analisadas. Os cemitérios oitocentistas brasileiros foram o campo privilegiado onde se realizou esta pesquisa: São João Batista, Cemitério da Ordem Terceira dos Mínimos de São Francisco de Paula (Catumbi), Cemitério da Ordem III de São Francisco da Penitência, Cemité- 
rio da Ordem III de N. S. do Carmo, Cemitério de São Francisco Xavier (Caju), todos no Rio de Janeiro; Cemitério da Consolação e Cemitério do Araçá, em São Paulo; Cemitério de Santo Amaro, no Recife; Cemitério do Campo Santo, em Salvador; Cemitério de Nossa Senhora da Soledade e Cemitério de Santa Isabel, em Belém; Cemitério de São João Batista, em Manaus.

Neles, a principal característica é a preservação e a conservação dos vestígios do morto, materializados nas construções grandiosas, decoradas com representações estatuárias e outros adereços. A presença de túmulos monumentais constitui por excelência a afirmação de uma posse simbólica do espaço cemiterial por parte de determinados segmentos burgueses da sociedade brasileira, na segunda metade do século XIX, que reivindicaram para si suas singularidades de classe pela recomposição dos liames familiares e, posteriormente, já nos primeiros decênios do século XX, pela progressiva individualização de seus membros em túmulos personalizados.

Em outras palavras, isso significa dizer que, quando surgem os primeiros cemitérios brasileiros, na segunda metade do século XIX, o que se vai notar é um crescente interesse por parte de algumas famílias em construir o próprio túmulo, nele reunindo seus descendentes diretos com o intuito de perpetuar a cadeia geracional. Por sua vez, o culto da memória era freqüentemente motivado pelo desejo de manter presente o morto no jazigo do grupo familiar, o que, de certo modo, reiterava a idéia de ser aquele lugar a continuidade da casa ou equivalente simbólico de unidade residencial da familia conjugal.

Nos primeiros decênios do século XX inicia-se uma significativa mudança nos hábitos de enterramento e, com ela, novas formas de morfologia tumular irão gradativamente marcar os espaços cemiteriais, refletindo-se também no plano das representações e das atitudes que os vivos passam a dedicar aos seus mortos. É dessa época o gosto pelo túmulo individualizado, construído especialmente para abrigar um único indivíduo, com o intento de evocar traços reveladores da pessoa do morto, traduzido como expressão de afeto particularizado.

\section{Espaço do morto e distinção}

\author{
[...] o morto mais se inaugura do que morre, e duplamente: ora \\ sua própria estátua ora seu próprio vivo[...]. \\ João Cabral de Melo Neto
}

Por volta do final da segunda metade do século XIX, o gosto pela sepultura individualizada tornouse importante referência para as elites brasileiras urbanas, que logo se adaptariam aos novos padrões de uso e apropriação dos espaços cemiteriais, assim como de suas lógicas de enterramento. Havia alguns anos já construídos, os primeiros cemitérios brasileiros secularizados passaram a concorrer entre si pela grandiosidade e luxo exibidos na construção de seus túmulos e jazigos. Cada um a seu modo tentou atrair para seus quadros de sepultamento as camadas mais afortunadas ligadas ao patronímico de velhas famílias que gozavam de prerrogativas econômicas e políticas decorrentes do comércio, da produção escravista, do latifúndio e de cargos importantes no poder. Anos mais tarde, seria a vez das novas fortunas, procedentes do capital financeiro especulativo, da indústria, de profissões liberais, assim como outros setores das camadas urbanas que surgiam nas principais capitais do país.

Enquanto o Cemitério da Ordem Terceira dos Mínimos de São Francisco de Paula, no Bairro do Catumbi, no Rio de Janeiro, inaugurado em 1850, tornara-se o lugar predileto para o sepultamento da elite nobiliárquica do Império, com seus marquezes, condes, barões, conselheiros, comendadores, tenentes-coronéis e outros titulares da guarda nacional, além de proprietários de terras e de escravos, o Cemitério de São João Batista, construído em 1852, no bairro de Botafogo, ocupou esse papel durante a República, acolhendo figuras importantes da vida pública do país: políticos, chefes de Estado, banqueiros, prósperos comerciantes, donos de renda, humanistas, militares, bem como segmentos da nova burguesia endinheirada da época (ver Valladares, 1972).

Mas, independentemente das afinidades eletivas, religiosas ou preferências político-ideológicas na escolha dos cemitérios, o fato é que tanto um quanto o outro foram exemplos privilegiados de representações diversas que as camadas mais abastadas 
buscaram construir sobre si mesmas por meio de edificações tumulares grandiosas, mediante as quais marcaram sua posição de classe e referendaram a origem de suas genealogias familiares. O processo de diferenciação e distinção nas formas de enterramento se reproduziu igualmente em três outros cemitérios do Rio de Janeiro. O primeiro deles é o Cemitério da Ordem III de S. Francisco da Penitência, inaugurado em 1858, que se manteve mais hierarquizado quanto ao perfil de seus usuários, na medida em que priorizou para sepultamento os membros da referida irmandade, entre os quais se destacavam muitos nomes conhecidos da República. O mesmo se poderia dizer do Cemitério da Ordem III de N. S. do Carmo, que passou a funcionar em 1857, reunindo uma clientela nobiliárquica proveniente tanto do Império como da República, além de destacadas figuras ligadas às novas profissões liberais. Já o Cemitério de São Francisco Xavier, também no Bairro do Caju, inaugurado em 1851, possuía uma freguesia bastante diversificada, composta por alguns nomes importantes da vida pública da época e também de profissões liberais, todavia, atraindo em bem maior número segmentos remediados e pobres da população.

Provavelmente, por ser na época o Rio de Janeiro a capital do país e, portanto, o centro de articulação do poder e das decisões políticas, teve igualmente o privilégio de abrigar o maior número de cemitérios, quando comparado a outros centros urbanos. Isto não quer dizer, todavia, que em outras capitais os cemitérios não constituíssem prioridades no processo de modernização e de transformação da malha urbana, reflexo evidente das políticas de salubridade que foram amplamente adotadas e difundidas na segunda metade do século XIX. Além disso, não se deve rejeitar a íntima relação entre alguns ciclos econômicos, que impulsionaram o crescimento de determinados centros urbanos do país, e a construção dos novos cemitérios.

O resultado mais concreto do processo de aburguesamento da sociedade brasileira, notadamente nos primeiros decênios do século XX, manifestavase de forma mais evidente no Cemitério da Consolação, na capital paulista, construído em 1856, considerado o mais tradicional da cidade por reunir tanto a velha elite, oriunda da burguesia quatrocentona cafeeira, como os novos empreendedores imigrantes no início do século XX. É preciso, todavia, assinalar que este cemitério conheceu fases distintas. $\mathrm{Na}$ primeira, preponderam os túmulos da nobiliarquia latifundiária, tanto da época do Império, como da República. Na segunda, sobressaem os mausoléus e as sepulturas monumentais de propriedade de grandes fortunas da indústria e do comércio, a maioria de origem imigrante. Diante desse quadro, os jazigos mais antigos, de cantaria portuguesa e italiana, de estruturas mais sóbrias e convencionais, característicos da primeira fase, foram ofuscados pelo luxo e a ostentação das construções tumulares posteriores, coincidindo com o apogeu do bronze como material de expressão artística. ${ }^{3}$

Não se observa tal fenômeno na mesma proporção e intensidade em outros centros urbanos do país, que somente por algum tempo chegaram a conhecer um período de relativa ascensão econômica, como foi o caso de Salvador e Belém, já que o Recife teve sua fase de maior apogeu econômico na transição do século XVIII para o século XIX. Nesses cemitérios o que se nota, entre outras coisas, são os jazigos imponentes, em mármore, da fase de consolidação que, em geral, vai de 1870 a 1900. Nos anos subseqüentes à sua inauguração, em 1851, o Cemitério de Santo Amaro, no Recife, passou a aglutinar um número significativo de nomes procedentes da velha burguesia rural, embora já em franca decadência, o que se reflete em muitas de suas construções tumulares de pequeno e médio porte, com parcos atrativos esculturais ou referências alegóricas. Mas nele há também notáveis exceções, destacando-se pela suntuosidade e imponência alguns mausoléus de propriedade dos chamados "barões do açúcar", proprietários latifundiários na zona do cultivo açucareiro. Processo análogo ocorreu em Belém, no Cemitério de Nossa Senhora da Soledade, inaugurado em 1853, atualmente desativado, que reuniu na época expressivos nomes ligados ao ciclo da borracha, assim como alguns túmulos construídos especialmente para abrigar os principais líderes da Cabanagem. Também na mesma cidade, o Cemitério de Santa Isabel, inaugurado em 1870, desempenhou papel importante na preservação da memória das camadas mais afortunadas, isto porque na época ainda reuniu alguns 
"barões da borracha", além de magistrados, comendadores, proprietários de ricos jazigos importados da Europa, os quais margeiam principalmente o eixo de sua entrada principal. Repetindo o mesmo processo de ostentação, o Cemitério do Campo Santo, em Salvador, por volta de 1855 passou a ser o local predileto de sepultamento das elites fundiárias baianas, de altos comerciantes e de destacados nomes ligados às profissões liberais e à política, sobressaindo alguns túmulos monumentais, muitos deles encomendados aos marmoristas de Lisboa, sobretudo no período entre 1855 e 1870.

Em vez do modelo anglo-saxônico, conhecido como cemitério jardim ou rural cemetery, no Brasil o esquema do urbanismo funerário seguiu de perto a orientação européia, repleto de estatuárias e de réplicas em miniatura inspiradas em construções passadas, para o qual o Père Lachaise e o Staglieno constituíam referências importantes. Dentro dessa linha de intenção e execução, os planos urbanísticos dos primeiros cemitérios brasileiros seguiram os modelos convencionais em voga na Europa, variando de acodo com a topografia em que foram erigidos. Visto no conjunto, o esquema predominante é o do traçado dividido em quadras regulares, entrecortadas por grandes alamedas e pequenas ruas, geralmente centrado por um cruzeiro ou capela de onde parte o eixo monumental ou central. Nesse eixo ou no seu entorno situam-se os mausoléus mais antigos e também os ossuários, em forma de urnas ou de obeliscos, transportados das igrejas para os novos locais de enterramento secularizados.

Como na cidade dos vivos, a desigualdade tornara-se ainda mais flagrante no espaço póstumo. Havia os bons e os maus lugares. Os mais caros e cobiçados, situados nas grandes alamedas ou avenidas centrais, cuja presença era notada e admirada por todos os que chegavam ao local, eram destinados àqueles que podiam pagar mais para ter o privilégio de um lugar especial e também de uma concessão perpétua, isto é, um patrimônio material transmissível como qualquer um outro: uma casa, um terreno, ou outros bens imóveis. Já os lugares mais recônditos, situados nas extremidades ou quadras laterais desses cemitérios, destinavam-se aos que tinham um poder aquisitivo menor, muitas vezes sem a concessão de transmissão.
Todo o esforço de agregar elementos escultóricos aos túmulos refletia não só o desejo de diferenciação por parte da família do morto, por meio da individualização do túmulo, marca distintiva de um patronímico, mas era também revelador de uma significativa mudança em relação aos hábitos e às expectativas diante da morte. Por volta da segunda metade do século XIX, as visitas aos cemitérios passaram a ser cada vez mais freqüentes e, com elas, o culto dos túmulos tornava-se prática familiar, a um só tempo afetiva e reputada como de boa conduta moral, sendo popularizadas por meio de crônicas e outros gêneros literários. Ciosas de seus privilégios, as camadas mais bem providas da época levaram às últimas conseqüências o projeto de materialização unicitária do túmulo, fosse ele individual ou de família, projeto influenciado na época por uma política de pacificação da morte que contemplava o respeito pelos rituais, individualização do luto e visitas freqüentes ao cemitério. E não é por coincidência que nessa época os túmulos de família, sob forma de capelas, conheceram o apogeu máximo nos cemitérios brasileiros, obrigando muitas vezes o indivíduo a abdicar de sua própria expressão de individualidade para se integrar ao grupo familiar, sob o pretexto de solidariedade e coesão, tendo como ancoragem principal o patronímico gravado com destaque no frontispício do jazigo, pois, de agora em diante, "não é mais a alma que é indestrutível, porém, a família, o sobrenome" (Ragon, 1981, p. 102).

\section{Mortos em família}

$$
\begin{aligned}
& \text { Tout graphéme est d'essence testamentaire } \\
& \text { JACQUES DERRIDA } \\
& \text { O epitáfio diz tudo } \\
& \text { Machado de Assis }
\end{aligned}
$$

Como toda marca, ou pedra de fundação, o túmulo é signo de uma inscrição primeira: marca, traço, escrita, origem. Não é por acaso que em grego a palavra sema, ao mesmo tempo, serve para designar signo e pedra tumular.

Construído em torno de um nome, geralmente do pai, o túmulo de família inscreve o indivíduo 
num passado comum, unindo-o a uma cadeia de gerações. É por isso que o morto deve abdicar parte de sua individualidade para se agregar a um nome ou sobrenome: o da família. O que prevalece nesse tipo de construção é a idéia do todo sobre as partes, buscando fortalecer laços entre os membros da família e, por sua vez, despertando nos vivos o sentimento de uma identificação comum, freqüentemente relacionada com uma casa ou unidade residencial, mesmo que esta já não mais exista.

O que se vê nas versões mais elaboradas desses túmulos é o desejo de unidade e continuidade que se impõe em face da segmentação e dispersão depois da morte, evitando, com isso, que os sepultamentos fossem realizados separadamente. Neles não importa o indivíduo isolado do seu grupo de filiação, mas o sujeito social genérico, constituído a partir da referência a um antepassado ou herança comum à qual se liga através de relações com seus ascendentes e descendentes.

Neste caso, o seu objetivo primordial seria reunir e conservar, depois de mortos, os membros pertencentes a uma mesma unidade familiar, podendo ser também extensivo a parentes secundários, a depender de cada caso. Os que ali se encontram sepultados abrigam-se sob um mesmo patronímico, gravado em lápide: dispositivo simbólico equivalente à coesão do grupo.

Do mesmo modo que nos cemitérios europeus, no Brasil também houve uma recepção positiva em relação aos túmulos de família, sobretudo depois de 1870. Tal morfologia recebeu interpretações diferenciadas, variando de acordo com as convicções de gosto e de classe social, algumas delas com referências cristãs, outras mais laicizadas, podendo variar também de estilos que iam desde as conhecidas capelas, passando por formas piramidais, reinterpretações de monumentos assírio-babilônicos, neogóticos, renascentistas, templos neoclássicos, ecléticos, de transição, até versões proto-modernas, depois substituídas pelas modernistas.

A referência tumular geralmente era determinada pela linha paterna, transmitida aos filhos, netos e bisnetos, podendo o sobrenome vir gravado muito discretamente ou visivelmente no frontispício do túmulo. Em muitos casos, o indicativo resumiase apenas a um patronímico, como por exemplo:
"Família Vaz Carvalhaes", "Família Carapebus", "Família Nioac", "Família De Mauá", "Sepultura da Família Agra", "Família S. Clemente", "Família Guinle", "Família Chamma".

Mas há também um detalhe importante que, de certa maneira, modificava a configuração onomástica do jazigo de família. Em alguns casos, em vez do sobrenome genérico de família, o que se tornava marca distintiva da inscrição tumular, era o próprio nome do pai e do marido fixado como a principal referência dos que ali se encontravam sepultados como, por exemplo, Jazigo Perpétuo de José Borges de Figueiredo e sua família. Vale salientar que tal referência geralmente dizia respeito à família conjugal, antes do matrimônio dos filhos, conforme exemplos freqüentes de nominação encontrados: "Jazigo Perpétuo de José Gomes de Pinho e sua Família", "Jazigo Perpétuo de Bernardo José da Cunha e sua Família”, "Jazigo Perpétuo de Joaquim Teixeira de Carvalho e sua Família".

Entretanto, após a dispersão dos filhos e o estabelecimento de novas famílias conjugais, as lógicas de enterramento estavam também sujeitas a modificações. Em muitos casos, os filhos varões estabeleciam novo túmulo de família, mantendo, todavia, o patronímico paterno. Há também situações em que os filhos preferiam criar novos segmentos, adotando uma referência patronímica secundária, adquirida por linha materna. Nessa linha de transmissão, a escolha de um sobrenome de referência na vida pública era, em algumas situações, medida pelo grau de prestígio que este chegava a adquirir, sendo, naturalmente, avaliado em função do benefício que traria à sua descendência. Nesses casos, isso também passava a orientar a lógica de adoção e inclusão do patronímico na construção de um novo túmulo.

Para este modelo de enterramento, observa-se o desejo de uma inscrição social baseada na aquisição de um novo status, seja por meio da riqueza, da posição social alcançada, seja, ainda, por meio dos títulos nobiliárquicos, como foi de praxe durante o Império, parte da República e no início do século $\mathrm{XX}$, conforme se pode encontrar em alguns túmulos: "Jazigo Perpétuo de Barão do Amparo e sua Família", "Sepultura Perpétua da família Barão de Andaray, Visconde de Andaray", Jazigo Perpétuo do Barão de Silveiras e sua Família", "Jazigo 
perpétuo dos Barões de Mangaratyba e seus descendentes", "Família do Conde de São Joaquim", "Jazigo da Família do Barão da Limeira".

No vasto quadro da onomástica tumular, observa-se a presença de alguns "nobres", de "ricos", "novos ricos", cada qual à sua maneira reinventando suas próprias raízes genealógicas. Entretanto, qualquer que fosse o caso em particular, era sempre um único indivíduo a ser valorizado. Para essas situações, o que de fato predominava era a prefixação do título honorífico representado sempre por uma referência individual da qual deveriam se beneficiar os seus descendentes. Já para outros proprietários de jazigos o que deveria prevalecer era o patronímico, respaldado no peso e na importância de uma profissão ou de uma tradição herdada. No início do século XX, em plena expansão de uma sociedade de classes, começava a ser invocado na epigrafia tumular o reconhecimento advindo da competência pelo trabalho e por mérito pessoal, muitas vezes adquirido em atividades laborais ou humanísticas.

O conjunto de dados onomásticos reunidos nas lápides, repetidas vezes, apelava à banalizada árvore genealógica, servindo tanto para avigorar as relações de parentesco como rememorar o grau de prestígio social de uma determinada família. No entanto, não se deve esquecer que toda memória genealógica irrompe à medida de sua própria conveniência, podendo também revelar-se através de outras interfaces, como lapsos, esquecimentos, restrições, seletividade. Afinal, não se recorda senão daqueles por que se tem interesse, pois, entre os antepassados há sempre o fascínio de se escolher aquele com quem se deseja identificar e, volta e meia, tal escolha é determinada pelo prestígio de um nome.

O lugar dos antepassados na cadeia genealógica, por razões óbvias, sempre ocupou um papel importante entre a aristocracia francesa, ao passo que para os segmentos burgueses o exercício genealógico, em muitos casos, não possuía nenhum interesse ou uma ação efetivamente prática. Mesmo assim, como já observou o historiador francês André Burguière (1991), algumas famílias burguesas do séculos XVII e XVIII buscaram reconstituir ou, de certo modo, reinventar suas raízes genealógicas, manipulando suas origens conforme seus propósitos e necessidades, com o intuito de criar novas identidades em razão do novo status socioeconômico adquirido. Para isso, preferiram realçar supostos sinais nobiliários do que exibirem o dinheiro como valor conquistado pelo esforço do trabalho - já que este último se tornara apanágio da burguesia da época.

Como ainda hoje se pode ver na maioria dos túmulos dos cemitérios aqui referidos, a epigrafia onomástica orienta-se pela ordem cronológica do óbito, resumindo-se apenas a informar o nome e o sobrenome do indivíduo, a data de nascimento e falecimento, acrescidos eventualmente de informações suplementares sobre a personalidade do morto. Além disso, a lógica de sepultamento, no interior de um túmulo de família, a maioria das vezes era orientada pelo princípio da consangüinidade, podendo nele reunir os ascendentes e os descendentes em linha direta (pai, mãe, filhos, avô e netos). ${ }^{4} \mathrm{~A}$ depender do caso, encontram-se incluídos alguns afins ou aliados. Em qualquer das hipóteses é pouco provável a existência de sepultamentos dos filhos oriundos de relações extras conjugais no interior desses jazigos, exceto quando são reconhecidos civilmente ainda em vida pelo pai ou quando consignados em testamento. ${ }^{5}$ Viúvas que contraíram matrimônio posterior, e com filhos do primeiro casamento, eram geralmente enterradas no túmulo de família erguido pelo primeiro marido ali sepultado. O mesmo não se verifica após a morte do cônjuge masculino de segundo casamento, que geralmente era sepultado no túmulo da família paterna ou em túmulo individual. Na hipótese de uma segunda união conjugal resultar em filhos comuns, a responsabilidade de decidir pelo enterramento do pai e padrasto no túmulo de família, herdado pela mãe na primeira união conjugal, caberia geralmente aos filhos mais velhos. ${ }^{6}$ Quando se tratava de indivíduos solteiros, ou eram sepultados em túmulos individuais ou se integravam ao jazigo de sua família de origem.

Com efeito, todo esse argumento, que aponta para o desejo de distinção, possessão material, reprodução e conservação de uma memória familiar, poderia ser também corroborado por outra importante variante ou representação do túmulo, isto é, uma possível analogia entre a casa e o jazigo. ${ }^{7}$ 
Quando a convivência e a familiaridade com os mortos deixaram de existir, quando estes foram levados para fora das cidades, sendo obrigados a deixar as igrejas e seus entornos, para os cemitérios, os túmulos passaram a preencher esse espaço anteriormente ocupado pela igreja. Como se sabe, era no interior desses templos, sobre um chão de adubado bumus cadavérico e sob a guarda de um teto divino, pintado de carregadas nuvens e de arcanjos suspensos, que a coletividade compartilhava momentos de intensa sociabilidade, não somente irmanada por crenças e devoções comuns, como também pelos rituais que celebravam: batizados, casamentos, aniversários de vida e de morte, confissões, comunhões, cíclos festivos e religiosos, procissões, velórios etc. Nos cemitérios, distantes de suas casas e igrejas, de suas paróquias, à céu aberto, os mortos encontrariam abrigos nos túmulos. Por isso, muitos deles reproduziram cenários de igrejas e de capelas, em escalas reduzidas, enquanto outros, com morfologias laicizadas, assemelhavam-se às residências de seus proprietários. Mas àquela altura não se tratava apenas de assegurar ao morto um lugar no céu, mas garantir também um lugar na terra, sob a proteção de uma coberta, aos cuidados da família, para lhe proteger das intempéries, e também resguardar a imagem de conservação do corpo. Nos túmulos acumulavam-se cadáveres, um ao lado do outro e não sobrepostos, cada um conservando parte de sua individualidade, mas sempre invocando lembranças comuns, memórias genealógicas, pois os túmulos passaram a ser também habitações familiares.

Se considerada dessa perspectiva, a casa e o túmulo de família cumpriam praticamente funções análogas, podendo ser interpretados como o lugar em que se reproduzia e se perpetuava o grupo familiar através de sucessivas gerações, assegurando-lhes a transmissão de um sobrenome, de bens materiais e imateriais, relações de poder, de autoridade e de hierarquia. Enquanto a casa poderia ser vista como locus de socialização da família, sendo, em alguns casos, capaz de reunir ao longo do tempo sucessivas gerações, integrando-as por meio de campos rituais diversos (nascimentos, batizados, formaturas, casamentos, aniversários, mortes, velórios, participação coletiva na elaboração do luto etc.), o túmulo, por sua vez, reproduzia no plano imagético o desejo de reunificar e perpetuar diferentes momentos de expressões coletivas da família e, com isso, fortalecer com sua dimensão simbólica o pacto de continuidade dos laços de parentesco entre seus membros. Visto desse ângulo, e a partir das bases sobre as quais se estruturavam as relações familiares, a morte do pai poderia também representar uma fratura econômica determinante na organização social do grupo familiar, interferindo igualmente no plano afetivo das relações domésticas. Quando isso ocorria, acarretava efeitos variados, podendo desencadear o processo de dissolução da família patriarcal, seja por meio de desavenças na partilha econômica dos bens, seja por meio de divergências na escolha de interesses e valores a ser seguidos. Mas, se de um lado a morte do pai era sempre uma ameaça, pois representava em certa medida a desarticulação econômica do grupo, interferindo inclusive na redefinição de novos papéis entre seus membros, de outro lado, era no túmulo onde se buscava corporificar, como espaço de representação, conservação e "presentificação" do morto, a reintegração de laços familiares e a neutralização de eventuais conflitos entre seus membros, uma vez que a casa já não mais conseguia cumprir tal papel.

Várias são as semelhanças entre as suntuosas casas senhoriais nas fazendas de café do Vale do Paraíba do Sul - algumas destruídas, outras atualmente sob domínio de estranhos - e os jazigos não menos opulentos de seus respectivos proprietários, muitos deles resistindo à ação do tempo, o que se pode comprovar ainda hoje nos cemitérios do Rio de Janeiro, especialmente no Catumbi, e na capital paulista, no Cemitério da Consolação.

Neste último cemitério, já em outro contexto econômico, um exemplo significativo do que se pretende enunciar é o túmulo do proprietário de fazendas cafeeiras, importador e empresário, o "Conde Alexandre Siciliano e de seus descendentes", em mármore branco, de autoria do escultor Amadeu Zani. Trata-se de uma reinterpretação de capela em estilo assírio-babilônico, encimada por figura alegórica no pórtico e vários detalhes leoninos, inclusive a presença de dois grandes leões guardiões que margeiam a entrada principal do mausoléu, símbolo de vigilância, muito freqüente nas casas senhoriais. Mas o que interessa destacar é a afinidade 
do túmulo com a residência do referido Conde, projetada, em 1896, pelo arquiteto Ramos de Azevedo, na Avenida Paulista. Talvez, o detalhe mais peculiar seja a transposição do universo doméstico para o espaço mortuário, como a presença de uma cadeira que o Conde costumava utilizar no seu cotidiano, com talha de sua heráldica no espaldar, bem como outros objetos decorativos.

Da Avenida Paulista já não resta quase nada da época de seu apogeu econômico, então dominada pelas vivendas da burguesia afortunada, cujo capital acumulado com o café era investido na produção industrial. A maioria de suas residências converteu-se em vistosos edifícios empresariais, mas a maior parte dos jazigos, pertencente aos antigos proprietários das velhas casas, ainda continua vivo testemunho de memórias familiares.

A casa do Conde Francisco Matarazzo e de sua família, um dos ícones da indústria brasileira, construída em meio a uma área de aproximadamente 12 mil metros quadrados, projetada pelos arquitetos italianos Giulio Saltini e Luigi Mancini, com o destacado brasão de família gravado no frontão principal da residência, atualmente abriga um enorme estacionamento, depois de sua demolição na década de 1980. Paradoxalmente, se o terreno dessa emblemática vivenda de família endinheira$\mathrm{da}$, que foi no passado, converteu-se temporariamente em grande garagem para carros, enquanto os herdeiros especulam sua venda, o mausoléu da família, no Cemitério da Consolação, parece cumprir o desejo de seu antepassado fundador, preocupado em eternizar sua linhagem. Ademais, a narrativa mítica de imigrante italiano bem-sucedido, com título nobiliárquico extensivo a cada um dos seus filhos varões, coaduna-se perfeitamente com o partido arquitetônico que orientou a construção do faraônico mausoléu, erigido em 1925, com peças em bronze de autoria do escultor genovês Luigi Brizzolara, e que até hoje cumpre o desígnio do poderoso chefe de família que pretendia reunificar e proteger o núcleo formado por seu nome, esposa e filhos, incluindo sua genitora. Com enorme cripta no subsolo, galerias laterais e capela no nível da rua, a construção de volume compacto ocupa uma área de mais de 150 metros quadrados de construção em blocos de mármore genovês, da oficina
L. Brizzolara, transportado de navio e remontado no local. Destaca-se dos demais pela exagerada escala, cujo ponto mais elevado ultrapassa os 15 metros do solo, onde se descortina o brasão da família.

Embora essa lógica de sepultamento tivesse como função precípua cultuar a memória dos antepassados, quase sempre conjugada a outros interesses do grupo, permitia também aos membros vivos da família se distinguirem socialmente a partir do habitat póstumo de seus parentes. Não se pode esquecer que a morte no mundo burguês, além de sua dimensão dramática, é também transmissão de um patrimônio, de uma herança, quando não material, simbólica. Por essa razão, no túmulo de família se configurava não apenas o desejo de continuidade e de perpetuação dos laços familiares, como igualmente se exibiam, por meio de sua arquitetura, na maioria das vezes suntuosa, signos de classe, marcando, assim, a posição social do morto e de seus descendentes.

Toda essa empreitada simbólica em eternizar a família surtia importante eficácia no plano intersubjetivo da recomposição de relações familiares, pois os túmulos possibilitavam aos membros de uma família, a depender de interesses particulares, se reconhecerem entre si, através de uma memória genealógica comum, ao mesmo tempo em que permitiam reconstituir e atualizar entre eles laços identitários, conforme fosse o caso. Mesmo se levando em consideração a descontinuidade de sepultamentos entre gerações, alguns desses jazigos, precários em seu estado atual de conservação, continuam ainda hoje, pelo menos no plano simbólico, representando esse último lugar mais perene através do qual algumas famílias ainda se permitem disfarçar os efeitos da decadência econômica, uma vez que seus bens materiais, incluindo as velhas residências, não suportaram as dinâmicas de transformação do sistema.

Conquanto a analogia entre cemitério e familistério fosse bem mais evidente durante toda a segunda metade do século XIX, apesar disso, já se podia observar nos últimos decênios desse mesmo século algumas das primeiras manifestações de individualidade, com renúncia pessoal de se integrar ao grupo de filiação, prática que se tornaria ainda mais freqüente nos primeiros anos do século XX. 
Assim, alguns túmulos suntuosos seriam construídos especialmente para abrigar uma única pessoa, ornados de representações alegóricas para marcar e eternizar a sua presença. A partir de então, cada vez mais, já não é a família que se tornava imperecível, tampouco o sobrenome, porém, o indivíduo.

\section{À flor da pedra}

j'écris, je ne veux pas mourir Georges Bataille

Écrire, c'est se sowvenir. Mais lire, c'est aussi se souvenir François Mauriac

Se o modelo de enterramento da família burguesa conheceu o seu apogeu durante a segunda metade do século XIX, com a "panteonização" de seus membros, por outro lado, foi nos primeiros decênios do século XX que insurgiu o culto ao indivíduo e sua contrapartida narcisista: os primeiros túmulos desvinculados de genealogias familiares. É em torno do indivíduo - que ora se complementa, ora se separa do núcleo familiar - que iriam se ordenar outras possíveis lógicas de sepultamento e, por sua vez, determinar a configuração arquitetônica dos novos túmulos, assim como também o campo de representações por meio do qual se exprimem as aspirações e as atitudes dos vivos em relação aos mortos.

Não que a família tenha desaparecido nesse novo modelo de enterramento, pois o indivíduo burguês, nessa época, emerge em sua singularidade a partir dos laços afetivos que mantém com o seu grupo familiar. Mas, além disso, ao seu redor começavam também a se criar expectativas e obrigações recíprocas, gerando relações baseadas tanto no princípio de pertencimento como de diferenças, o que, em algumas situações, o obrigava a redefinir papéis sociais que hierarquicamente deveria ocupar no contexto doméstico e, de forma correlata, na esfera pública. Tais atribuições sociais podiam ser visualizadas nos túmulos que agora mostravam representações mais particularizadas e que abrangiam tanto aspectos ligados à vida em família, como à vida do "amor conjugal", do "amor materno e filial”, do respeito pelo legado material e imaterial de um parente longevo; quanto aos aspectos relacionados com o próprio indivíduo: o enaltecimento de virtudes pessoais, da promoção de valores adquiridos pelo trabalho, da competência profissional etc.

O que se observa a partir dos primeiros decênios do século XX é um progressivo distanciamento do modelo anterior, calcado basicamente no reconhecimento de laços consangüíneos por meio da procriação, na importância patronímica, como elemento diferenciador e de prestígio social, e no interesse corporativo de perpetuar vínculos parentais. ${ }^{8}$ Ainda em relação à noção de família anteriormente descrita, vários são os autores que sublinham a importância do caráter autoritário como motor das relações familiares centradas no poder de um chefe, o que não só inibia como, muitas vezes, impedia que se concretizassem laços afetivos e emocionais entre seus membros. Refletia-se inclusive na opção pela escolha dos jazigo-capelas, equivalentes simbólicos das casas, que dada a natureza de suas morfologias austeras mascaravam expressões de afeto particularizadas, o que nos túmulos individuais seriam exacerbadas. É também recorrente se associar a esse modelo de família o ideal de matrimônio subordinado aos interesses econômicos e de reprodução social do grupo, em vez da união conjugal por motivação afetiva que começava a se impor entre os indivíduos e que, pouco a pouco, se converteria em padrão recorrente.

Enquanto nos modelos mais convencionais do túmulo de família deveriam ser evitadas possíveis marcas valorativas de seus membros, singularidades que eventualmente pudessem conflitar entre si ou até mesmo atrair e dirigir as atenções do espectador para um único componente do grupo de filiação - pois em princípio todos eles deveriam receber tratamento posicional -, no túmulo construído para um único indivíduo ou casal, sobressaía o desejo de valorizar e enaltecer determinados atributos da pessoa do morto, ocultando outros indesejáveis. $\mathrm{O}$ que mais parecia importar era o desejo de auto-expressão subjetiva, de auto-reconhecimento ou reconhecimento de um outrem como sujeito singular. Em algumas situações, o morto poderia ser representado como sujeito autônomo, cujo grau de independência não necessitava ser partilhado nem dividido, sob pena de perder suas próprias características. 
Paulatinamente, neste novo contexto, a família vai se rendendo diante da individualidade de seus membros. A depender de cada situação em particular, começa-se a deslocar o interesse das relações de parentesco para o das relações intersubjetivas aspecto que se reflete ainda mais nas novas formas de enterramento nos cemitérios-parques e nos cemitérios verticais.

Há casos em que os túmulos refletem expressamente o desejo de alguém que aspira depois da morte ser lembrado por suas ações e realizações sob a aspiração de ser, posteriormente, convertido em síntese edificadora de memória e de reconhecimento coletivo. Nesse gênero de epitáfio autobiográfico é comum atribuir-se ao indivíduo qualidade de pessoa, o que pressupõe sua construção a partir de uma dimensão sociocultural particular e, portanto, vinculada a um sistema simbólico e de representações também específico - representações cujos dispositivos rituais muitas vezes costumam conferir a essa noção tanto atributos de identidade como valorativos. ${ }^{9}$ Nos cemitérios ocidentais, à pessoa do morto se costuma adicionar epítetos diversos, sendo invocados entre outros aspectos aqueles de foro mais íntimo, e também a capacidade de ser moral e civil. É por isso que repetidas vezes no léxico tumular são ressaltadas qualidades como: pessoa de "mérito", "digna", "honesta", "caridosa”, “espiritual", "benfeitora", "honrada", "íntegra”, "fraternal", "justa", "trabalhadora" etc.

Vários são os exemplos nos cemitérios aqui referidos em que os méritos pessoais são evocados, sobretudo aqueles advindos do esforço pelo trabalho, sendo igualmente acompanhados de alegorias representativas da pessoa do falecido. Talvez, um dos modelos mais significativos da ideologia de valorização do trabalho seja o túmulo erigido no cemitério do Araçá, em São Paulo, pelo próspero comerciante de cereais, Antonio Lerario.

Como muitos outros imigrantes de origem italiana, Antonio chegou à cidade de São Paulo para tentar a vida. O túmulo erigido por ele, em blocos de granito escuro, sobre os quais se apóiam placas de bronze em alto relevo, narram sua trajetória, destacando como principal conteúdo da mitologia funerária a ascensão social via trabalho incansável e penoso. Suas raízes campesinas, dominadas pela paisagem rural, ainda na terra natal, a Itália, são representadas por cenas de semeadura, cultivo e colheita de trigo, servindo como leitmotiv para as três primeiras placas que servem de vedação nos locais de enterramento, situadas na base do túmulo.

Em posição de destaque, as demais placas compõem outra seqüência narrativa na qual se evidencia a construção mítica do herói, concebida por méritos próprios. Na primeira, no topo do volume vertical, a cena evoca a partida. Ao que tudo indica, em busca de maiores oportunidades, Antonio decide ganhar a vida em outro continente. $O$ rosto voltado para trás, com um guarda-chuva apoiado sobre o braço esquerdo e a mão direita acenando para o pai e a mãe que retribuem com o mesmo gesto ao filho que parte. Na próxima cena, já no navio que o leva ao Brasil, o jovem apóia os braços sobre o guardacorpo da embarcação, segurando com as duas mãos a cabeça num gesto contemplativo: olha sem ponto fixo no espaço. $\mathrm{Na}$ alegoria seguinte, na capital paulista, Antonio inicia sua nova vida como jornaleiro nas ruas. Na mão, o jornal levantado é oferecido a dois senhores devidamente caracterizados como da elite local bem-sucedida, à qual o próprio imigrante logo se integrará. A alegoria final é representada pela figura de Antonio, homem maduro, afortunado comerciante de cereais, com evidentes inscrições sociais da burguesia ascendente, em meio a dois trabalhadores que carregam sacas de cereais. Ao fundo da cena as sacas empilhadas sugerem a base da riqueza, ao mesmo tempo, produto convertido pelas virtudes do próprio esforço pessoal, legado que provavelmente pretendia deixar como mensagem aos descendentes que posteriormente se incorporariam ao túmulo comum.

É interessante, todavia, ressaltar que a mesma ênfase não se verifica em exemplos análogos, de imigrantes igualmente bem-sucedidos, que preferiram construir suas mitologias funerárias calcadas menos no esforço e conquista pelo trabalho penoso - velho apanágio da burguesia - do que na legitimação de um ethos aristocrático, como fez o Conde Matarazzo, seguido por outros quadros da burguesia oriunda do comércio e da indústria paulista.

A alegoria ao trabalho e à fortuna reaparece também de forma mais genérica ou difusa, servindo como elemento decorativo em alguns túmulos, 
sobretudo no Cemitério da Consolação, em São Paulo, e no São João Batista, no Rio de Janeiro, algumas vezes sob formas de signos alusivos ao comércio e à indústria (máquinas de tecelagem, equipamentos industriais, bigornas, peças de montagem, produtos de consumos etc.), outras vezes referentes à produção agrícola e à pecuária (café, cacau, borracha, cana-de-açúcar, animais de corte etc.), a depender das atividades laborais do proprietário do túmulo. A alusão ao trabalho é também valorizada como qualidade humanitária da pessoa do falecido, especialmente quando se trata dos túmulos de médicos, advogados, engenheiros, bem como de outras atividades técnicas menos reconhecidas.

O mesmo se poderia dizer em relação aos túmulos de figuras ligadas ao mundo das artes, da música e da literatura. Ainda no mesmo patamar, poderse-ia incluir aqueles que desempenhavam atividades de notório reconhecimento público ou simplesmente "mortos ilustres" como, por exemplo, políticos, militares, governantes, chefes de Estado etc. ${ }^{10}$

A emulação dos "grandes vultos", geralmente realizada pela representação épica, adquire dimensão de panteão em alguns cemitérios, já que uma das funções da imaginação histórica é edificar mitos e, portanto, promover o culto cívico ou patriótico. Esse gênero de túmulo-monumento cumpria também seu papel civilizador, posto a serviço ideológico da construção do Estado-nação brasileiro no final do século XIX e nos anos subseqüentes, reforçando o sentimento coletivo de pertencimento cívico na construção de uma identidade e memória nacionais. ${ }^{11}$ Quando se tratava de heróis, mortos a serviço da pátria, as representações dos túmulos deveriam fazer alusão aos signos de força, grandeza, glória, honra, virilidade e outros atributos do gênero. Tanto maior fossem a sua bravura e o sacrifício pela pátria, mais reconhecimento e importância adquiriam a pessoa do morto, sendo promovida à nobre categoria de mártir nacional. A modalidade que lhe era reservada no monumento poderia variar entre o cívico e o patriótico, dependendo da grandeza de suas ações, o que certamente lhe promoveria a um monumento individual, quando se tratava de um destemido personagem; ou coletivo, quando inserido em um determinado grupo a serviço da pátria. ${ }^{12}$
Mas, se as mortes dos heróis eram vistas como nobres e grandiosas, raramente acidentais, pois a coragem e a previsibilidade do perigo faziam parte da própria condição mítica do sacrifício heróico, a morte das pessoas comuns não despertava o mesmo sentimento. Não mais a "bela morte", mas a "boa morte" por causas "naturais", sem dor nem sacrifícios, modelo ideal disseminado por todo o século XVIII. A forma e as circunstâncias em que uma pessoa comum deixava o mundo dos vivos assumiam um papel determinante na compreensão, no significado e no sentido que os mais próximos costumavam exprimir em relação à pessoa do morto, refletindo em particular na escolha da forma tumular.

A depender da situação, o que se observa é a preferência pela construção de túmulo individual, de pequena proporção, como testemunho afetivo da família ao membro desaparecido, podendo assumir características diferenciadas quando se tratava de uma morte esperada, em que o túmulo e suas representações estatuárias geralmente adquiriam uma dimensão de recompensa subjetiva pelo legado material e imaterial deixado pelo morto. Mas o que dizer quando a morte sobrevinha em circunstâncias inesperadas, considerada desastrosa? Nestes casos, as representações tumulares são mais propensas à dramatização. Muito freqüente nos cemitérios são os túmulos construídos para as mães cuja morte súbita deixara órfãos filhos ainda pequenos. A representação da figura materna geralmente reproduz cenas do convívio doméstico, cercada pelos filhos. Quando a figura masculina, esposo e pai, morto também em circunstâncias inesperadas, torna-se o objeto de representação, é figurado sob forma de busto ou em placa de alto relevo, a que se atribui sentido épico, muito comum durante todo o século XIX. Em outras situações, o busto masculino vem acompanhado de representação tridimensional da viúva, algumas vezes cercada pelos filhos, em gesto de reverência à figura do marido e do pai falecido. Quando se deseja imprimir maior dramaticidade à perda, a figura masculina torna-se ausente na representação para em seu lugar aparecer em destaque a figura feminina pranteadora.

As alegorias também costumam refletir lugares de gênero, isto é, as esferas socialmente atribuídas 
ao masculino e ao feminino. Às mulheres, uma identidade ligada à maternidade e às atividades domésticas; aos homens, a competência na esfera da vida pública e do trabalho. ${ }^{13}$ A partir dos primeiros decênios do século XX, começam a surgir, de forma pontual e com destaque no conjunto estatuário, representações masculinas tridimensionais geralmente associadas ao trabalho e à vida pública. Quando vinculadas a situações ou a cenas da vida privada, geralmente se limitam a invocar algum tipo de legado moral ou espiritual, como nas representações em que aparece a figura do avô com o neto, referência cronológica e valorativa de conhecimentos e valores morais transmitidos.

O tributo ao "amor conjugal" é outro tema freqüente nas alegorias tumulares. No amplo quadro de representações é comum se ver a figura de matronas, encobertas com véus ou mantilhas, cujas expressões faciais podem variar entre o pranto e o desconsolo explícitos e o recolhimento introspectivo e sereno do luto. A expressão do personagem pode se alterar conforme o sentimento que o proprietário do túmulo gostaria que fosse transmitido como mensagem: ora é a figura feminina que se estende ou se debruça inconsolável sobre o túmulo ou esquife do marido, ora situações nas quais prevalecem sentimentos difusos que vão da melancolia ao êxtase.

Cada um a seu modo, os túmulos individuais buscavam reconstituir por meio de representações traços ou elementos que pudessem identificar o morto como único e insubstituível, restituindo no plano imagético tanto momentos ou cenas importantes da vida, como a lembrança de circunstâncias sinistras em que a pessoa foi subtraída do convívio mais próximo. Devido à diversidade e à riqueza com que se apresentam os túmulos nos cemitérios aqui referidos, seria impossível reagrupar todas as categorias de representação encontradas. Entre elas, todavia, chamam a atenção em especial aquelas que expressam situações em que a morte surpreende pela violência. Nesses casos, diferentes valores são evocados como atributos positivos à pessoa do morto, podendo incidir sobre a honra, a idade, a coragem, a sensibilidade, convergindo de forma positiva para a construção individual da mitologia funerária.
Como a morte acidental ou provocada, a morte de jovens e crianças é também inadmissível para a maioria das sociedades ocidentais de tradição cristã, em muitos casos sendo-lhes reservados túmulos à parte que não os das respectivas famílias. Quando se tratava de recém-nascidos, o acontecimento era freqüentemente inserido no plano da crença dos "anjinhos", que provavelmente encontra suas raízes no catolicismo popular. ${ }^{14}$ De acordo com esse tipo de representação, a alma infantil, dado o seu estado de "inocência originária", ascendia mais facilmente à imortalidade, sendo corriqueiramente associada à figura dos anjos, tal como aparece na maioria das alegorias funerárias. Em alguns cemitérios, ainda hoje se observa em determinadas áreas uma maior concentração de túmulos reservados às crianças, povoados de representações de meninos com asas (os putti), pequenos querubins e serafins, espaços provavelmente previstos em seus projetos iniciais para enterramento de crianças e recém-nascidos - local chamado de Cripti di Bambini nos cemitérios italianos.

Quando a morte sobrevinha na primeira infância, as representações infantis passavam a ser outras, pois as crianças já começavam a possuir uma identidade própria, passando a ser vistas como pessoas singulares: além de um nome, um direito reconhecido, um lugar ou papel determinado, uma idade cronológica e algumas funções específicas na vida familiar. Em muitos casos, também não deveriam integrar o túmulo de família, sendo sepultadas em jazigos individuais, especialmente concebidos para eternizar sua presença na terra e marcar o convívio entre os familiares. As representações variavam em função das circunstâncias da morte e do grau de afeto familiar. Geralmente no lugar dos anjos, o que se vê são representações de crianças que realçam suas singularidades de pessoa, retratadas tanto de forma realista como metaforizada por meio de alegorias: crianças em suas atividades escolares, crianças brincando, acompanhadas dos irmãos, crianças sendo levadas pelos anjos etc.

Já em relação aos adolescentes ou aqueles que morreram ainda jovens, o tratamento simbólico, quando representados sob formas escultórias, muda completamente. Isto porque os jovens de alguma forma já integravam o mundo dos adultos, com identidades sexuais definidas, inclusive aptos à 
procriação. Além disso, suas funções e atribuições tornavam-se mais específicas no âmbito da família e das relações sociais mais amplas, frustrando com a morte expectativas futuras. Em alguns casos, integravam os jazigos de família, outras vezes, a depender das circunstâncias da morte, eram-lhes erigidos túmulos individuais com o intuito de cultivar e preservar uma mitologia funerária pessoal.

No final da primeira metade do século XX, as construções tumulares, pouco a pouco, deixaram de constituir prioridades de investimento relacionadas com a distinção social de algumas famílias, a identificação e a transmissão de um patronímico comum, a atualização de laços identitários, o culto à memória. Do mesmo modo o túmulo individual também passou a comportar outras expectativas e interesses, subtraindo à pessoa do morto referências alegóricas.

Uma das tendências foi tornar os túmulos mais versáteis, funcionais e menos decorativos, com capacidade de renovação nos locais de enterramento, já que suas morfologias também deveriam se nortear por princípios racionais, adequados então às pequenas dimensões dos lotes ainda disponíveis que, a depender do cemitério, poderiam atingir altos valores especulativos. As novas construções passaram a ocupar toda a extensão do terreno, com proporções que permitem apenas abrigar um determinado número de sepultamentos, sendo substituídos à medida das novas necessidades de inumação de seus proprietários, e com isso refletindo as novas dinâmicas de composições familiares. Antigos túmulos foram refeitos para atender às necessidades práticas de seus herdeiros ou de novos compradores.

Simultaneamente ao crescimento demográfico das cidades e da expansão da economia mortuária, emergiram outros espaços de enterramento alternativos, com concepções arquitetônicas e paisagísticas inteiramente diferenciadas. A nova tendência é de que nenhuma evidência alegórica alusiva à conservação do corpo do morto deve se tornar elemento constitutivo da paisagem cemiterial. Nas versões dos cemitérios-parque ou jardim, predominam as campas-chão, com aberturas horizontais, na altura do solo, com dimensão exata do corpo humano, que comportam de uma a três inumações em lages sobrepostas. As superfícies externas são recobertas por gramado com uma discreta sinalização no local de inumação. O mesmo princípio aplica-se aos cemitérios verticais, em que os lóculos para inumação se distribuem pelos andares, alocando os mortos de uma mesma família pelos corredores dos diferente pavimentos. Mas tanto em um quanto no outro, a lógica acumulativa de enterramentos, e também de presentificação, como nos antigos túmulos de família, desaparecem completamente.

Já a cremação, que vem ganhando adeptos nos últimos anos, parece impor ainda mais novos desafios em relação ao tratamento dispensado ao morto e suas formas de recordá-lo. É possível conservar a lembrança de alguém sem um signo material referente à sua existência ou sem a memória de objetos que o evoquem? Muito prontamente poderia alguém retrucar que o verdadeiro túmulo está muito mais presente na memória dos vivos, ou no cemitério dos vivos, a ser cultivado no interior de cada indivíduo, do que na representação alegórica dos restos mortais de uma pessoa.

Há várias forma de se recordar. Um álbum de fotos, um eventual objeto de estimação herdado, um sonvenir de viagem, uma música, um livro, um aroma não seriam também capazes de evocar a lembrança de alguém desaparecido e, ao seu modo, render-lhe homenagem? Mas para isso sempre necessitamos de alguém que nos recorde, e por certo aí reside um dos fantasmas de quem vive: o medo de ser esquecido.

$\mathrm{Na}$ medida em que os antigos cemitérios não se renovam, tendem cada vez mais a se tornar vestígios arqueológicos, atrativos de curiosidade muselógica, lugar de memórias residuais, o que já há algum tempo atrás metaforizava Marcel Proust ao comparar um livro a um grande cemitério, no qual sobre a maior parte de seus túmulos não se pode mais ler os nomes apagados. Talvez por isso, para muitos, a descontinuidade na cadeia geracional represente ainda hoje uma constante ameaça, como a situação vivida por uma mulher, já bastante idosa, que no São João Batista, no Rio de Janeiro, costuma dedicar horas semanais a cuidar do túmulo de seu único filho, morto na juventude. Entretanto, lastima que não lhe restando muitos dias pela frente, nem laço algum de família, pois todos os seus já se foram, o nome do filho pouco a pouco perderá os 
contornos na pequena lápide, e sem nervuras, como uma grande mancha impalpável, não tardará a alcançar por completo toda a superfície lisa da pedra, juntando-se a outros nomes apagados.

Mas independentemente das imagens que suscita e dos meios que os vivos mobilizam para superá-la, a morte é sempre ruptura radical, por isso ainda hoje continua sendo objeto de uma série de atitudes ritualizadas, senão coletivas, individualizadas, mesmo que as morfologias tumulares, as dinâmicas sociais e seus sistemas de representação em nada mais se assemelhem às dos antigos cemitérios, que buscavam eternizar, por meio da pedra e de outros elementos alegóricos, os elos intersubjetivos que a morte foi capaz de desagregar.

\section{Notas}

1 Equipamento móvel criado nos Estados Unidos, na década de 1970, cujo objetivo é expor os corpos dos defuntos em vitrines a fim de que os familiares e amigos possam do próprio interior do automóvel contemplar o morto e registrar suas condolências em livro, sem a necessidade de sair do veículo. Experiência homóloga à do conhecido drive-in que se destina ao consumo de fast food, propagadas por todo mundo através de cadeias como McDonald's e similares.

2 Trecho do poema O defunto, da autoria de Pedro Nava. Trata-se de cópia dada pelo autor a Manuel Bandeira, posteriormente incluído no livro organizado pelo poeta pernambucano, intitulado Apresentação da poesia brasileira (1946, pp. 384-387).

3 É importante assinalar que o Cemitério do Araçá, construído em 1897, passou a ser palco de enterramento de segmentos médios da população e de profissionais liberais, muito deles imigrantes. O Cemitério do Brás, em 1880, tornou-se com o tempo lugar de inumação popular, conservando um grande contingente de origem italiana. Já o Cemitério São Paulo, no bairro de Pinheiros, construído na década de 1930, foi planejado para receber uma parte da elite empresarial e progressista que emergia com força a partir dos anos de 1940 até a década de 1960.

4 O direito de quem pode e deve ser sepultado em um jazigo de família já foi estudado por João de Pina Cabral, em contexto contemporâneo, sob a perspectiva da gestão das sepulturas por algumas famílias burguesas da cidade do Porto. A noção de que "o sangue é mais denso do que a água" (máxima predileta de David Schneider: "blood is thicker than wather"), identificada por Pina Cabral como categoria recorrente entre as famílias burguesas do Norte de Portugal para "descrever a sua vida familiar", parece também constituir uma referência importante na lógica de enterramento nos túmulos de família aqui referidos, embora em outro contexto histórico (ver Pina-Cabral, 1991).

5 É o que se depreende da leitura de alguns testamentos de famílias tradicionais da segunda metade do século XIX, no Rio de Janeiro e Pernambuco. Em geral, o testador identifica-se pelo nome e estado civil, número e nome dos filhos, após instituir o destino do corpo e o local da sepultura.

6 Foram realizados contatos com alguns descendentes de proprietários de túmulos em alguns dos cemitérios pesquisados. A escolha foi pela antiguidade e prestígio de algumas conhecidas famílias. No universo pesquisado, só foi possível localizar e ter acesso apenas àqueles mais idosos, que forneceram informações a respeito dos critérios adotados em relação aos que poderiam ou não ser enterrados no túmulo pertencente às suas famílias. Em alguns casos, o contato foi estabelecido com aqueles que ainda se ocupavam com tarefa de zelar pela conservação do túmulo ou que visitavam mais freqüentemente o local.

7 Sobre esses assunto, ver Freyre (1951); Ariès, "Du sentiment moderne de la famille dans les testaments et les tombeaux", artigo apresentado no Colóquio sobre Familia, realizado em Cambridge, em setembro de 1969 e depois incluído no livro Essais sur l'bistoire de la mort en Occident, 1975, pp. 141-142.

8 Sobre as transformações da idéia de família na sociedade contemporânea, isto é, de liames familiares a serviço do indivíduo e da identidade pessoal, ver Sangly (1996a e b), Théry (1999), Roussel (1989). Esses autores, cada um à sua maneira, reforçam a tese de uma individualização familiar baseada na "desinstitucionalização" do grupo familiar, isto é, de que a família não mais se funda a partir do respeito a um passado ou a um projeto comum, tampouco sobre a vontade de perpetuar uma linhagem, passando doravante a se organizar de forma mais estritamente pessoal e relacional sobre a qual prevalece a idéia de indivíduo.

9 No espaço desse ensaio não cabe aprofundar uma reflexão sobre a noção de pessoa, tal como foi elaborada na antropologia por Marcel Mauss, Lévy-Bruhl, Maurice Leenhardt e, mais recentemente, por outros antropólogos contemporâneos, como Louis Dumont, 
entre outros. Tal noção será retomada em próximo trabalho. Sobre o assunto, consultar as referências já consagradas: Mauss ([1929] 1969; [1938] 1950). Ver também C. Carrithers, C. Steven e L. Steven (1985).

10 Sobre esse assunto, consultar o trabalho de Bonnet (1986).

11 Sobre o culto cívico e patriótico, evidenciado na construção de monumentos aos mortos, é interessante consultar o artigo de Prost (1984).

12 No caso brasileiro, a panteonização dos heróis combatentes quase sempre encontra-se vinculada às forças armadas: exército, marinha e aeronáutica, ações de combate muito limitadas. Já no continente europeu, a Primeira e a Segunda Guerra mundiais marcaram profundamente a concepção de monumento, concorrendo para que se passasse da celebração individual do herói para a celebração coletiva das vítimas. Isto não ocorreu no Brasil, haja vista a participação secundária das forças armadas nacionais na Segunda Grande Guerra, o que inclusive resultou na construção de monumento coletivo aos soldados desaparecidos em parque do Rio de Janeiro. No que diz respeito à Europa, ver Volvelle (1988).

13 A este respeito, consultar Bronfen (1975); Rahme (2000).

14 Provavelmente, o simbolismo dos "anjinhos" tem origem na Península Ibérica, posteriormente influenciando o imaginário popular de países latino-americanos. Com o barroco, é possível que tenha se difundido ainda mais essa crença, devido à abundante representação de cunho religioso nas igrejas, assim como o papel dos jesuítas no processo missionário entre os povos indígenas. Sobre as representações da morte infantil, consultar Ariès (1973).

\section{BIBLIOGRAFIA}

ARAUJO, A. C. (1997), A morte em Lisboa: atitudes e representaçôes (1700-1830). Lisboa, Editorial Notícias.

ARIÈS, P. (1973), L'enfant et la vie familiale sous l'Ancien Régime. Paris, Seuil.

. (1975), Essais sur l'histoire de la mort em Occident. Paris, Seuil.

Seuil. . (1977), L'bomme devant la mort. Paris,

AUZELLE, R. (1965), Denières demeures : conception, composition, realization du cimetière contemporain. Paris, Mazarine.

BANDEIRA, M. (1946), Apresentação da poesia brasileira. Rio de Janeiro, CEB.

BARRAU, A. (1992), Socio-économie de la mort: de la prévoyance aux fleurs de cimetière. Paris, L'Harmattan.

BAUDRILLARD, J. (1976), L'echange sybolique et la mort. Paris, Galliamard.

BEATY, N. L. (1970), The craft of daying: a study in the literary tradition of the ars moriendi in England. New Haven, Yale University Press.

BENDER, T. (1988), “The 'rural' cemetery movement: urbain travail and the appeal of nature", in Robert B. St. George (ed.), Material life in America 1600-1860, Boston, Northeastern University Press, pp. 505-519.

BERTRAND, F. (1994), Politiques de la mort, politiques urbaines: évolutions et enjeux. Belleville, DEA de projet architectural et urbaines, École de Paris.

BENDANN, E. (1930), Death customs: an analytical study of burial rites. Nova York, Knopf.

BERGER, A; BADHAM P.; KUTSCHER, A. H.; BERGER, J.; PERRY, M. \& BELOFF, J. (eds.). (1989), Perspectives on death and dying: cross-cultural and multi-disciplinary views. Philadelphia, Charles Press.

BLOCH, M. (1971), Placing the dead: tombs, ancestral villages, and kinship organization in Madagascar. Londres/Nova York, Seminar Presss.

BLOCH, M. \& PARRY, J. (eds.). (1982), Death and the regeneration of life. Cambridge, Cambridge University Press.

BOASE, T. S. R. (1972), Death in the middle ages: mortality, judgement and remembrance. Nova York, McGraw-Hill.

BONNET, J-C. (1986), "Les morts illustres: oraison fúnebre, éloge académique, nécrologie", in P. Nora (org.), Les lieux de mémoire. II La Nation, Paris, Gallimard.

BORG, A. (1991), War memorials from antiquity to the present. Londres, Leo Cooper.

BORGES, M. E. (2002), Arte funerária no Brasil (1890-1930): ofício de marmorista italianos em Ribeirão Preto. Belo Horizonte, C/arte.

BOWKER, J. (1991), The meaning of death. Cambridge, Cambridge University Press.

BOWMAN, L. E. (1959), The American funeral: a stu- 
dy in guilt, extravagance and sublimity. Washington, DC, Public Affairs Press.

BRONFEN, E. (1975), Over her dead body: death, femininity and the aesthetic. Manchester, Manchester University Press.

BROCK, J. \& SCHWARTZ, S. J. (1991), "A litlle slice of heaven: investigations at Rincon Cemetery". Historical Archeology, 25 : 78-90.

BROOKS, C. (ed.). (1989), Mortal remains: the history and present state of Victorian and Edwardian cemetery. Londres, Victorian Society.

BROWN, J. G. (1994), Soul in the stone: cemetery art from America's heartland. Kansas, University Press of Kansas.

BROWN, I. W. (1992), “The New England Cemetery as a cultural landscape", in Steven I. Lubar e David W. Kingery (eds.), History from things: essays on material culture, Wahington, Smithsonian Institution.

BUNNEN, L. \& SMITH, V. W. (1991), Scorin in heaven: gravestones and cemetery art of the american sunbelt states. Nova York, Aperture.

BUNTING, C. (1982), The happy funeral. Nova York, Haper and Row.

BURGUIÈRE, A. (1991), "La mémoire familiale du Bourgeois Gentilhomme: généalogies domestiques en France aux XVII ${ }^{\text {ème }}$ et XVIII ${ }^{\text {ème }}$ siècles". Annales ESC, 4: 771-788, jul.-ago.

BURNS, S. B. (1990), Sleeping beauty: memorial photography in America. Altadena, CA, Twelvetree Press.

CAHIER de Saint-Maximin \& COLLÈGE d'Echanges Contemporains. (1974), La mort aujourd'bui. Marseille, Editions Rivages.

CARRITHERS, M.; STEVEN, C. \& STEVEN, L. (orgs.). (1985), The category of the person: anthropology, philosophy, history. Cambridge, Cambridge University Press.

CATROGA, F. (1990), “A cremação na época contemporânea e dessacralização da morte: o caso português". Revista de História das Idéias, 8: 223262, Coimbra. (1999), O céu da memória: cemitério romântico e memória. Coimbra, Minerva.

CEDEROTH S.; CORLIN, C. \& LINDSTRÖM, J. (orgs.). (1989), On the meaning of death: essays on mortuary rituals and eschatological belief. Stockholm, Almqvist et Viksell.
CHAPMAN, R.; KINNES, I. \& RANDSBORG. K. (1981), The archaeology of death. Cambridge, Cambridge University Press.

CHARBOT, A. (1988), Érotique du cimetière. Paris, Henri Veyrier (col. Les Plumes du Temps).

CHARLOT, M. (1976), Vivre avec la mort. Paris, Alain Moreau.

CHARMAZ, K. (1980), The social reality of death in contemporary America. Reading, MS, AddisonWesley.

CHAUNU, P. (1978), La mort à Paris: $16^{\text {ime }}, 1^{\text {ime }}, 1^{\text {ime }}$ siècles. Paris, Fayard.

CHORON, J. (1969), La mort et pensée occidentale. Paris, Payot.

CLARK, D. (ed.). (1993), The sociology of death: theory, culture, practice. Oxford, Blackwell.

COATES, C. M. (1987), "Monuments and memories: the evolution of Britsh Columbian Cemeteries 1850-1950". Bulletin d'Histoire de la Culture Matérielle, 25: 11-19.

COLVIN, H. (1991), Architecture and the after-life. New Haven/Londres, Yale University Press.

CORMACK, R. (1997), Painting the soul: icons, death masks and shrounds. Londres, Reaktion.

CURL, J. S. (1980), A celebration of death: an introduction to some of the buildings, monuments and settings of funeray architecture in the Western Eurpean tradition. Londres, Constable. (1972), The Victorian celebration of death. Detroit, Partridge.

DAVIES, D. (1997), Death, ritual and belief. Londres, Cassell.

DÉCHAUX, J-H. (1997), Le souvenir des morts: essai sur le lien de filiation. Paris, PUF.

DÉCHAUX, J-H.; HANUS, M. \& JÉSU, F. (eds.). (1998), Les familles face à la mort : entre privatisation er resocialisation de la mort. Paris, L'Esprit du Temps.

DETHLEFSEN, E. S. (1981), "The cemetery and culture change archaelogical focus and ethnographic perspective", in Richard Goud e Michael B. Schiffer (eds.), Modern material culture: the archeology of US., Nova York, Academic Press, pp. 137-159.

DOUCET, L. (1974), La foire aux cadavres. Paris, Denoël.

DROZ, Y. (2003), La violence et les morts: eclairage anthropologique sur les rites funéraires, Paris, Georg Editeur. 
DRAPER, J. W. (1984), The funeral elegy and the rise of English romanticism. Londres, Hodder and Stoughton.

DUMONT, R. (1973), L'utopie ou la mort. Paris, Seuil.

DUNK, J. \& RUNG, J. (1994), The management of Old Cemetery Land. Londres, Shaw and Son.

ELIAS, N. (1985), The loneliness of the dying. Oxford, Blackwell.

ELLIOT, G. (1972), The Twentieth Century book of the death. Nova York, Random House.

ETLIN, R. A. (1984), The architecture of death. Massachusetts/Londres, The Massachusetts Institute of Tecnology.

FARRELL, J. J. (1980), Investing the American way of death: 1830-1920. Philadelphia, Temple University Presss.

FEIFEL, H. (1977), News meanings of death. Nova York, McGraw-Hill.

FEIJÓ, R.; MARTINS, H. \& PinA CABRAL, J. (orgs.). (1985), A morte no Portugal contemporâneo: aproximaçoes sociológicas, literárias e históricas. Lisboa, Editorial Querco.

FEINSTEIN, D. \& MAYO, P. E. (1990), Rituals for living and dying. San Francisco, Haper and Row.

FIELD, D.; HOCKEY, J. \& SMALL, N. (eds.). (1977), Death, gender and ethnicity. Londres, Routlege.

FINUCANE, R. C. (1996), Ghost: appearences of the death and cultural transformation. Nova York, Prometheus Books.

FLORES, M. F. (1993), Cemitérios de Lisboa: entre o real e o imaginário. Lisboa, Câmara Municipal de Lisboa.

FRASCARI, M. (1981), "The iconic relationship between cemetery and town", in W. Sterner (ed.), Image and code, Michigan, University of Michigan, pp. 147-168.

FREYRE, G. (1951), Sobrados e mucambos. Rio de Janeiro, José Olympio.

FULTON, R. L. \& BENDIKSON, R. (1994), Death and identity, Philadelphia, Charles Press.

GEDDES, G. E. (1981), Welcome joy: death in puritan New England. Ann Arbor, MI, UMI Research Press.

GILBERT, M. (org.). (2005), "Antigone et le devoir de sépulture". Actes du Colloque International de l'Université de Lousane, Genève, Editions Labor et Fides.
GILI, M. (ed.). (1999), La última casa, trad., Barcelona, Editorial Gustavo Gili.

GITTINGS, C. (1988), Death, burial and individual in early modern England. Londres, Routledge.

GNOLI, G. \& VERNANT, J-P. (orgs.). (1982), La mort, les morts dans les sociétés anciennes. Paris/Cambridge, Maison des Sciences de l'Homme/Cambridge University Press.

GOODWIN, S. \& BRONFEN, E. (eds.). (1993), Death and representation. Baltimore, Johns Hopkins University.

GOODY, J. (1962), Death, property and the ancestors: a study of the mortuary customs of the LoDagaa of West Africa. Stanford, CA, Stanford University Press. (1996), L'bomme, l'écriture et la mort: entretiens avec Pierre-Emmanel Daurart. Paris, Les Belles Lettres.

GORER, G. (1965), Death, grief and mourning in contemporary Britain. Londres, The Cresset Press.

GUIART, J. (org.). (1979), Les hommes et la mort: rituels funéraires à travers le monde. Paris, Le Sycomore/ Objets et Mondes.

GUTHKE, K. (1999), The gender of death. Cambridge, Cambridge Universty Press.

HABENSTEIN, R. W. \& LAMERS, W. M. (1962), The history of American funeral directing. Milwaukee, Bulfin.

HALLAN, E.; HOCKEY, J. \& HOWART, G. (1999), Beyond the body: death and social identity. Londres, Routledge.

HERTZ, R. (1960), Death and right hand. Londres, Cohen and West.

. (1980), "Contribution à une étude sur la représentation collective de la mort", in Paris, PUF. , Sociologie religieuse et folklore [1928],

HINTERMEYER, P. (1981), Politiques de la mort. Paris, Payot.

HOCKEY, J. (1990), Experiences of death: an anthropological account. Edimburgh, Edimburgh University Press.

HOULBROOKE, R. (ed.). (1989), Death ritual and bereavement. Londres, Routledge/Social History Society.

HOWARTH, G. (ed.). (1996), Last rites: the work of the modern funeral director. Amityville/Nova York, Baywood. 
HOWARTH, G. \& JUPP, P. C. (1996), Contempora$r y$ issues in the sociology of death and dying. Londres, Macmillan.

HUMPHREYS, S. C. (1983), The family, women and death: comparative studies. Ann Arbor, University of Michigan Press.

HUMPHREYS, S. C. \& KING, H. (orgs.). (1981), Celebrations of death: the anthropology and archeological of death. Nova York, Academic Press.

HUNTINGDON, R. \& METCALF, P. (1979), Celebrations of death: the anthropology of mortuary ritual. Cambridge, Cambridge University Press.

IRISH, D. P.; LUNDQUIST, K. F. \& NELSON, V. J. (eds.). (1993), Ethnics variations in dying, death and grief: diversity in university. Washington, DC, Taylor \& Francis.

JACKSON, C. O. (ed.). (1977), Passing: the vision of death in America. Westport, CT, Greenwood Press.

JONES, B. (1967), Desing for death. Indianapolis, Bobbs-Meril.

JUPP, P. C. (1990), From Dust to Asch: the replacement of burial by cremation in England, 1840-1967. Londres, The Congregation Memorial Hall Trust.

JUPP, P. C. \& GITTINGS, C. (1999), Death in England: an illustrated history. Manchester, Manchester University Press.

KASTENBAUM, R. \& KASTENBAUM, B. (1989), Encyclopedia of death. Phoenix, Arizona, Oryx Press.

KEARL, M. (1989), Endings: a sociology of death and dying. Nova York, Oxford University Press.

KEISTER, D. (1997), Going out in style: the architecture of eternity. Nova York, Facts on File.

KüBler-Ross, E. (1975a), On death and dying. Nova York, Macmillan.

. (1975b), Death: the final stage of growth. Englewood Cliffs, Prentice Hall.

LIMA, T. A. (1994), "De morcegos e caveiras a cruzes e livros: a representação da morte nos cemitérios cariocas do século XIX". Anais do Musen Paulista, 2, Nova Série, São Paulo.

LITTEN, J. (1991), The English way of death: the common funeral since 1450. Londres, Robert Hale.

LLEWLLYN, N. (1992), The art of death: visual culture in the English death ritual, 1500-1800. Londres, Victoria and Albert Museum.

LOFTLAND, L. (1976), Towards a sociology of death and dying. Berverly Hills, Sage.
. (1978), The craft of dying: the modern face of death. Berverly Hills, Sage.

MACHADO, C. A. (1999), Cuidar dos mortos. Sintra, Instituto de Sintra.

MAERTENS, J. T. (1979), Le jeu du mort (ritologiques): essai d'anthropologie des inscriptions du cadavre. Paris, Aubier Montaigne.

MARTINS, J. de S. (org.). (1983), A morte e os mortos na sociedade brasileira. São Paulo, Hucitec.

MAUREILLE, B. (2004), Les origines de la culture: les premières sépultures. Paris, Le Pommier.

MAUSS, M. (1921), "L'expression obligatoire des sentiments (Rituels oraux funéraires Autraliens)". Journal de Psychologie, 18: 425-434, Paris. ([1929] 1969), "L'âme, le nom et la personne", in Oeuvres 2, Paris, Éditions de Minuit, pp.131-142.

([1938] 1950), "Une catégorie de l'esprit humain: la notion de personne, celle de "moi"', in _ Sociologie et anthropologie, Paris, PUF, pp. 331-362.

MCMANNERS, J. (1981), Death and enlightenmet: changing attitudes to death among christians and unbelievers in Eigteenth-century France. Oxford, Oxford University Press, 1981.

MENAHEM, R. (1973), La mort apprivoisée, Paris, Presses Universitaires.

MEYER, R. E. (org.). (1985), Cemeteries and gravemarkers: voices of American culture. Londres, UMI Research Press.

MITFORD, J. (2000), The American way of death revisited. Nova York, Vintage Books.

MOLLER, D. W. (1996), Confronting death: values, institutions, and buman mortality. Nova York, Oxford University Press.

MORIN, E. (1970), L'bomme et la mort. Paris, Seuil. MORLEY, J. (1971), Death heaven and Victorians. Londres, Studio Vista.

O'CONNOR, M. C. (1942), The art of dying well: the development of the ars Moriendi. Nova York, Columbia University Press.

PINA-CABRAL, J. de. (1991), "A família burguesa do Porto: a gestão das sepulturas", in Difel. , Os contextos da antropologia, Lisboa,

PINE, V. R. (1975), Caretaker of the death: the American funeral director. Nova York, Irvington. 
PRIOR, L. (1989), The social organization of death. Basingstoke, Macmililan.

PROST, A. (1984), "Les monuments aux morts: culte républicans? Culte civique?, Culte patriotique?", in P. Nora (org.), Les lieux de mémoire. I. La république, Paris, Gallimard, 1984.

PUCKLE, B. S. (1926), Funeral customs: their origin and development. Londres, Laurie.

RAGON, M. (1981), L'espace de la mort: essai sur l'architecture, la décoration et l'urbanisme funéraires. $\mathrm{Pa}$ ris, Albin Michel.

RAHME, A. M. A. K. (2000), Imagens femininas em memória à vida: a escultura nos cemitérios da Consolação, Araçá e São Paulo, de 1900 a 1950. São Paulo, dissertação de mestrado em Arquitetura, Universidade de São Paulo.

REIS, J. J. (1999), A morte é uma festa: ritos fúnebres e revolta popular no Brasil do século XIX. São Paulo, Cia das Letras.

RENN, D. (ed.). (1998), Life, death and money: actuaries and the development of social and finacial markets. Oxford, Blakwell.

RODRIGUES, C. (1997), Lugares dos mortos na cidade dos vivos: tradição e transfomações fúnebres no Rio de Janeiro. Rio de Janeiro, Secretaria Municipal da Cultura.

- (2005), Nas fronteiras do além: a secularização da morte no Rio de Janeiro (séculos XV III e XIX). Rio de Janeiro, Arquivo Nacional.

ROUSSEL, L. (1989), La famille incertaine. Paris, Odile Jacob.

ROWELL, G. (1974), Hell and victorians: a study of Nineteenh Century theological controversies concerning eternal punishment and future life. Oxford, Clarendon Press.

RYLANDS, W. H. (1881), The ars moriendi: a reproduction of the copy in the British Museum. Londres, Wyman.

SANGLY, F. (1996a), Sociologie de la famille contemporaine. Paris, Nathan. ris, Nathan.

SAWDAY, J. (1996), The body emblazoned: dissection and the buman body in Renaissance culture. Lodres, Routledge.

SEALE, C. (1989), Constructing death: the sociology of dying and bereavement. Cambridge, Cambridge University Press.
SLOANE, D. C. (1991), The last great necessity: cemeteries in American history. Baltimore, Johns Hopks University Press.

STANNART, D. (1977), The Puritan way of death. Nova York, Oxford University Press.

STEWART, G. (1984), Death sentences: styles of dying in British fiction. Cambridge, MA, Harvard University Press.

SUDNOW, D. (1967), Passing on: the social organization of dying. Englewood Cliffs, Prentice Hall.

TAYLOR, L. (1983), Mourning dress: a costume and social history. Londres, Allen and Unwin.

THÉRY, I. (1999), "Famille: une crise de l'institution". Notes de la Fondation Saint-Simont, 83, set., Paris.

THOMAS, L-V. (1976), Anthropologie de la mort. Paris, Payot.

. (1978), Mort et pouvoir. Paris, Payot. (1982), Le cadavre. Paris, Payot.

(1985), Rites de mort: pour la paix des vivants. Paris, Fayard. . (1988), La mort. Paris, PUF (col. Que sais-je).

TODD, J. Gender, Art and Death, New York, Continuum, 1993.

VALLADARES, C. do P. (1972), Arte e sociedade nos cemitérios brasileiros. Rio de Janeiro, Conselho Federal de Cultura/MEC.

VERNANT, J-P. (1998), "Prolégomènes, la mort ou les morts?", in O. Dumoulin e F. Thelamon (orgs.), Autour des morts: mémoire et identité, Rouen, Université de Rouen.

VERNON, G. (1970), Sociology of Death. Nova York, Ronald Press.

VOVELLE, M. (1974), Mourir autrefois: attitudes collectives devant la mort aux XVII'me et XVIII' ìme siècles. Paris, Gallimard/Julliard. (1983), La ville des morts: essai sur l'imaginaire urbain contemporain d'aprés les cimetières provençaux. Paris, Éditions du Centre National de la Recherche Scientifique. - (1988), La mort et l'Occident, de 1330 à nous jours. Paris, Gallimard. . (1981), "Le Deuil Bourgeois. Du faire-part à la statuaire funéraire". Le Débat, 12:6082, Paris, Gallimard.

WILSON, A. \& LERY, H. (1938), Burial reform and funeral cost. Londres, Oxford University Press. 
URBAIN, J-D. (1978), La societé de conservation: étude sémiologiques des cimetières de l'Occident. Paris, Payot, 1978.

- (1998), L'archipel des morts: le sentiment de la morte et les dérives de la mémoire dans les cimetièrs d'Occident. Paris, Éditions Payot/Rivales.

XAVIER, P do A. (2001), A morte: símbolos e alegorias. Lisboa, Livros Horizonte.

ZIEGLER, J. (1975), Les vivants et la mort. Paris, Seuil. 
FORMAS TUMULARES E PROCESSOS SOCIAIS NOS CEMITÉRIOS BRASILEIROS

\section{Antonio Motta}

Palavras-chave: Cemitérios; formas tumulares; Processos sociais; Parentesco.

Este trabalho focaliza vários níveis de correlação entre formas tumulares e processos sociais, sobretudo no que diz respeito às composições familiares e de parentesco, calcadas no desejo de assegurar uma continuidade na ordem familiar por meio de uma memória genealógica comum. Busca também analisar e interpretar a transição das lógicas de sepultamento centradas na família para um novo modelo baseado no individualismo.

\section{TOMB FORMS AND SOCIAL PROCESSES IN BRAZILIAN CEMETERIES}

\section{Antonio Motta}

Keywords: Cemeteries; Tomb forms; Social processes; Kinship.

This study emphasizes several levels of correlation between tomb forms and social processes, especially with respect to kin and family compositions based on the desire to assure continuity of family order by way of a shared genealogical memory. It also seeks to analyse and interpret the transition from burials cemtered on the family to a new model based on individualism.

\section{FORMES DES TOMBEAUX ET PROCESSUS SOCIAUX DANS LES CIMETIÈRES BRÉSILIENS}

\section{Antonio Motta}

Mots-clés: Cimetières; Formes des tombeaux; Processus sociaux; Parenté.

Ce travail met l'accent sur plusieurs niveaux de rapports entre la forme des tombeaux et les processus sociaux, notamment, en ce qui concerne les compositions familiales et de parenté, basées sur l'intention d'assurer une continuité de l'ordre familial à travers une mémoire généalogique commune, en même temps $\mathrm{qu}^{1}{ }^{1} \mathrm{il}$ cherche aussi à analyser et interpréter la transition des logiques d'enterrement: de la famille vers l'individualisme. 